\title{
EFFECT OF STAGGERED ROUGHNESS ELEMENTS ON FLOW CHARACTERISTICS IN RECTANGULAR CHANNEL
}

\author{
Elnikhely E.A ${ }^{1}$ \\ ${ }^{1}$ Lecturer, Water and Water Str. Eng. Dep., Faculty of Engineering, Zagazig University, Zagazig University, Zagazig, \\ Egypt
}

\begin{abstract}
Flow characteristics are measured experimentally on an artificially roughened bed in a horizontal flume. The pattern; of roughness are staggered arrangements. The water surface profile is recorded at different sections. This paper investigated the effects of using fiberglass sheets as roughness elements for staggered arrangement, on different flow characteristics. Compared to the smooth bed, it is observed that the roughness bed decreases the relative jump depth by $22 \%$, increases the relative energy loss by $14 \%$, and reduces the relative jump length by $8.1 \%$. The experimental results achieved promising results regarding each of dissipating energy; the relative jump length as well as the relative jump depth in addition to the coefficient of discharge. The derived formulas for relative depth and the relative energy loss that satisfactorily agree with the experimental data are proposed. Prediction equations were developed using the multiple linear regression (MLR) to model the hydraulic jump characteristics.
\end{abstract}

Keywords: Experimental, Theoretical, Flow characteristics, Bed roughness

\section{INTRODUCTION}

Hydraulic jump is one subject which has extensively been studied in the field of hydraulic engineering. It is an intriguing and interesting phenomenon. The cost of the basin which confines the whole length of free jump is very high. As a result, roughness elements were usually installed in the basin itself to reduce the jump length and to increase the energy loss by increasing turbulence. It may play as damping members for the jump. Characteristics of flow under the effect of roughness were investigated by several theoretical and experimental models include Rajaratnam (1964), Pillai and Unny (1964), Rajaratnam (1968), Leutheusser and Schiller (1975), Peterka (1978), Ranga Raju (1980), Hughes and Flack (1984), and Abdelsalam et al. (1986), Mohamed Ali (1991) and Negm et al. (1993). Alhamid (1994) investigated experimentally different hydraulic jump characteristics formed on an artificially roughened bed. It was concluded that $12 \%$ roughness density provides the optimal length of basin for the flow conditions. Ead and Rajaratnam (2002) indicated that the length of jumps on corrugated beds is less than its length over smooth one. Evcimen (2005) determined the effect of different roughness types and arrangements on hydraulic jump characteristics in a rectangular channel. The bed friction effect on the stability of a stationary hydraulic jump was investigated by Defina and Susin(2008) in a rectangular upward sloping channel through a combined theoretical and experimental approach. A numerical scheme provided by turbulence models was used by Abbaspour et al (2009) to predict the 2-D water surface location, flow velocity distribution, and the bed shear stress for jump on a corrugated bed. Elsebaie and Shabayek (2010) studied the effect of different shapes of corrugated beds on the characteristics of hydraulic jumps for all shapes of corrugated beds, they found that the length of the jump on the different corrugated beds was less than half of that on smooth beds and the integrated bed shear stress on the corrugated beds was more than 15 times that on smooth beds. The jump upon four adverse slopes in two cases of rough and smooth bed was examined by Nikmehr and Tabebordbar (2010). The results showed that the sequent depth ratio and the length of jump upon smooth bed has been more than rough bed for the same slopes and Froude numbers. Tokyay et al. (2011) found that the roughness elements considerably reduce the sequent depth and length of the hydraulic jump. AboulAtta et al. (2011) used T-shape roughness instead of the regular cubic one. They found that the T-shape roughness save materials and reduce the jumplength compared to the cubic one. Ezizah et al. (2012) tested a new roughness shape (U-shap). Sun and Ellayn (2012) found that the staggered roughness is more efficient than strip roughness. Esfahani and Bejestan (2012) found that the roughening bed of stilling basin can reduce the jump length by about $40 \%$. Thus the present study investigates experimentally the effect of staggered sheets as roughness elements on flow characteristics. The water surface profile is recorded at different sections. Habib and Nassar (2013) found that the apron of $90 \%$ staggered roughness length increases the relative energy loss by $17 \%$.

\section{EXPERIMENTAL SETUP}

Experiments were carried out in the Hydraulics Laboratory of the Faculty of Engineering, Zagazig University, Egypt. It was accompanied in a flume of $0.30 \mathrm{~m}$ wide, $0.50 \mathrm{~m}$ deep with an overall length of about $12.0 \mathrm{~m}$. The discharges were measured using a pre-calibrated orifice meter fixed in the main flow line. The tailgate was fixed at the end of the experimental part of the flume which used to control the tail-water depth. The water depths were measured by means of point gauges. Figure (1) presents a typical arrangement of 
the staggered roughened bed to show the distribution of the roughness element over the channel bed. The experimental program is summarized in table (1), it is including two stages. Stage I can be described as the base case. It includes the case of smooth bed without any modifications. It included about 39 experimental runs. Stage II explores the effect of the staggered roughened elements on the flow characteristics for different variable depths, $(\mathrm{Hr}=0.5,0.75$, 1.0 , and $1.5 \mathrm{~cm})$. It included about 24 experimental runs.
The test procedure consisted of the following steps:

The discharge and desired gate opening were set; the position of the jump was adjusted; the flow rate and the water surface profile were recorded; the length of jump, $\mathrm{Lj}$, was measured in each case. The Froude number ranges between 3.3 and 8.6 .

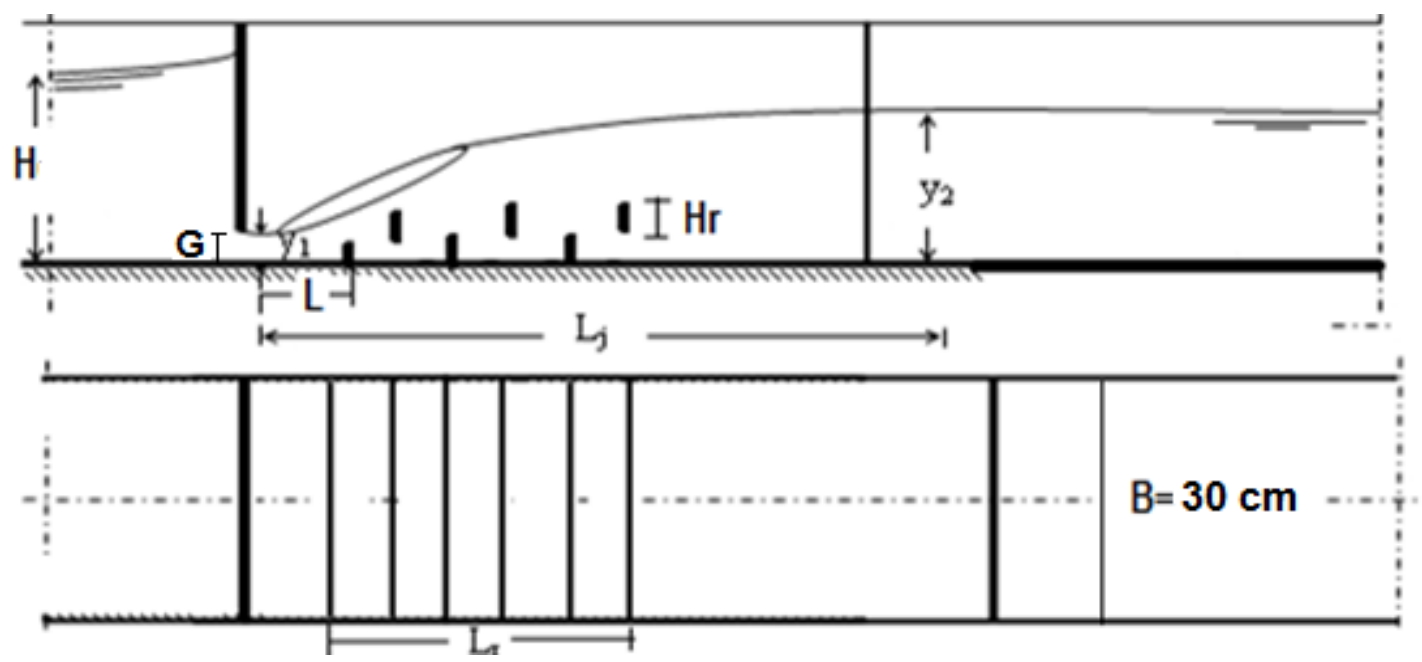

Fig 1: Schematic diagram of the experimental model

Table 1: Scheme of experimental work stages

\begin{tabular}{|c|c|c|c|c|}
\hline Stage & Description & $\begin{array}{l}\text { Cha } \\
\mathbf{H}_{\text {mar }} \\
(\mathrm{mm}\end{array}$ & $\begin{array}{l}\mathbf{a c t e r i} \\
\mathbf{H r} \\
(\mathrm{cm})\end{array}$ & $\begin{array}{l}\text { tics } \\
\mathbf{G} \\
\mathrm{cm})\end{array}$ \\
\hline I (39 runs) & The smooth case & $\begin{array}{l}40 \\
35 \\
30 \\
25 \\
3.3 \\
3.5\end{array}$ & 0 & $\begin{array}{c}2.1 \\
2.3 \\
2.6 \\
3.0\end{array}$ \\
\hline II (24 runs) & The effect of the depth of the staggered roughness elements & $\begin{array}{l}40 \\
40 \\
40 \\
40 \\
40 \\
40\end{array}$ & $\begin{array}{l}0.5 \\
0.75 \\
1.0 \\
1.5\end{array}$ & $\begin{array}{c}2.1 \\
2.3 \\
2.6 \\
3.0 \\
3.3 \\
3.5\end{array}$ \\
\hline
\end{tabular}

\section{THEORETICAL APPROACH}

\subsection{Dimensional Analysis}

The flow field downstream of a roughened apron (bed with staggered sheets) DS of the sluice gate depends on a large number of flow variables as shown in figure (1). A dimensional analysis is applied to correlate the different variables affecting phenomena under study and the following functional relationship is obtained:

$$
\frac{y_{2}}{y_{1}}=f\left(\frac{H_{r}}{y_{1}}, F_{1}\right)
$$

$$
\frac{L_{j}}{y_{1}}=f\left(\frac{H_{r}}{y_{1}}, F_{1}\right)
$$

And

$$
\begin{aligned}
& \frac{\Delta E}{E_{1}}=f\left(\frac{H_{r}}{y_{1}}, F_{1}\right) \\
& C_{d}=f\left(\frac{H_{r}}{y_{1}}, \frac{H}{G}\right) .
\end{aligned}
$$


in which $\mathrm{y}_{2} / \mathrm{y}_{1}$ is the relative jump depth; $H_{r} / y_{1}$ is the relative depth of the roughened element; $F_{1}$ is the initial Froude number $; \mathrm{F}_{1}=\mathrm{v}_{1} /\left(\mathrm{gy}_{1}\right)^{0.5} ; \mathrm{L}_{\mathrm{j}} / \mathrm{y}_{1}$ is the relative length of the free jump; $\Delta E / E_{1}$ is the relative energy loss through the free jump, and $C_{d}$ is the coefficient of discharge.

\subsection{The Relative Depth of Jump $\left(\mathrm{y}_{2} / \mathrm{y}_{1}\right)$}

Both the 1-D momentum and continuity equations are used to develop a theoretical design model for computing the relative depth ratio. The approach involves the following assumptions: the flow is steady, the liquid is incompressible, and the pressure distribution is hydrostatic at the beginning and at the end of jump.

Also, the velocity distribution at the beginning and the end of the jump is uniform. The turbulence effect and the air entrainment are neglected. Actually, the main assumption of the theoretical model is that it deals with the projection of roughness elements. By applying the pressure-momentum relationship in the longitudinal direction one gets (see Fig.1):-

$$
\Sigma F=\rho Q\left(\beta_{1} V_{1}-\beta_{2} V_{2}\right)
$$

$$
\mathrm{P}_{2}+\mathrm{P}_{\text {rough. }}-\mathrm{P}_{1}=\frac{\gamma}{g}\left(Q \beta_{1} \mathrm{~V}_{1}-Q \beta_{2} \mathrm{~V}_{2}\right)
$$

Where:

$$
\begin{array}{r}
\mathrm{P}_{2}=0.5 \times \gamma B y_{2}^{2} \ldots \ldots \ldots \ldots \ldots \ldots \ldots \ldots \ldots \ldots \ldots \ldots \ldots \ldots \ldots \ldots \ldots \\
\mathrm{P}_{1}=0.5 \times \gamma B y_{1}^{2} \ldots \ldots \ldots \ldots \ldots \\
\mathrm{P}_{\text {rough }}=\sum_{i=1}^{i=n} \gamma H_{r} \times y_{\text {rough }} \times B
\end{array}
$$

In which: $B$ :channel width; $\mathrm{P}_{2}$ :hydrostatic pressure just downstream of the jump; $\mathrm{P}_{1}$ :hydrostatic pressure just upstream of the jump; $\mathrm{P}_{\text {rough }}$ : the total hydrostatic pressure on the roughness elements; $y_{1}$ :initial depth of the jump; $\mathrm{y}_{2}$ :sequent depth of the jump; $y_{\text {rough }}$ : the diference between water depths US and DS the roughness element; $H_{r}$ : the height of the roughness element and $n$ is the number of roughness elements in the lateral direction. Substituting in equation (6) yields.

$$
0.5 \times \gamma B y_{2}^{2}+\sum_{i=1}^{i=n} \gamma H_{r} \times y_{\text {rough }} \times B-0.5 \times \gamma B y_{1}^{2}=\frac{\gamma}{g}\left(Q \beta_{1} v_{1}-Q \beta_{2} v_{2}\right)
$$

For simplification of equation (10), it can be rewritten in the following form.

$$
0.5 \times \gamma B y_{2}^{2}+m \gamma H_{r} y_{\text {avrough }} B-0.5 \times \gamma B y_{1}^{2}=\frac{\gamma}{g}\left(Q \beta_{1} v_{1}-Q \beta_{2} v_{2}\right)
$$

In which: ${ }^{y_{\text {avrough }}}$ : the average difference between water depths upstream and downstream the roughness elements. Assuming that $\beta 1=\beta 2=1.0$ and applying the continuity equation between section (1) and section (2):

$$
0.5 \times \gamma y_{2}^{2}+n \gamma H_{r} y_{\text {avrough }}-0.5 \times \gamma y_{1}^{2}=\left(\gamma \times v_{1} y_{1} / g\right)\left(v_{1}-v_{1} y_{1} / y_{2}\right)
$$

Dividing Eq. (12) by $0.5 \times \gamma \times y_{1}^{2}$, Let, $H_{r} / y_{1}=h_{r}$, and $\mathrm{y}_{\text {avrough }} / \mathrm{y}_{1}=\mathrm{y}_{\mathrm{rr}}$

where : $y_{2} / y_{1}$ :relative depth of jump; $h_{r}$ : relative roughness element's height; $y_{r r}$ : relative water depth over the roughness element.

$$
\left(\frac{y_{2}}{y_{1}}\right)^{2}+2 n h_{r} y_{r r}-1=\frac{2 \mathrm{~V}_{1}^{2}}{y_{1} g}\left(1-\frac{y_{1}}{y_{2}}\right)
$$

Equ. (13) can be written as:

$$
\left(\frac{y_{2}}{y_{1}}\right)^{2}+2 n h_{r} y_{r r}-1=2 F_{1}^{2}\left(1-\frac{y_{1}}{y_{2}}\right)
$$

\subsection{Energy Approach}

The energy loss can be obtained by applying the energy equation as follows:

$$
\Delta E=E_{1}-E_{2}
$$

Where $E_{1}$ is the specific energy just upstream the free jump, (i.e., $E_{1}=y_{1}+\alpha_{1} V_{1}^{2} / 2 g$ ) and $E_{2}$ is the specific energy downstream the free jump (i.e., $E_{2}=y_{2}+\alpha_{2} V_{2}^{2} / 2 g$ ), $\alpha_{1}$ is the energy coefficient at beginning of the jump and $\alpha_{2}$ is the energy coefficient at end of the jump. Assuming that; $\alpha_{1}=\alpha_{2}=1.0$. 
$\frac{\Delta E}{E_{1}}=1-\frac{E_{2}}{E_{1}}=1-\frac{y_{2}+V_{2}^{2} / 2 g}{y_{1}+V_{1}^{2} / 2 g}=$
$1-\left[\left(y_{2} / y_{1}+V_{2}^{2} / 2 y_{1} g\right) /\left(1+V_{1}^{2} / 2 y_{1} g\right)\right]$

$\frac{\Delta E}{E_{1}}=1-\frac{\frac{y_{2}}{y_{1}}+B^{2} y_{1}{ }^{2} V_{1}^{2} / B^{2} y_{2}{ }^{2} 2 y_{1} g}{1+\frac{F_{1}^{2}}{2}}$

$=1-\left[\frac{y_{2}}{y_{1}}+\frac{F_{1}^{2}}{2\left(\frac{y_{2}}{y_{1}}\right)^{2}} / 1+\frac{F_{1}^{2}}{2}\right]$

$$
\frac{\Delta E}{E_{1}}=1-\left[\left(\frac{y_{2}}{y_{1}}\right)+F_{1}^{2} \times \frac{1}{2}\left(\frac{y_{1}}{y_{2}}\right)^{2} /\left(1+\frac{F_{1}^{2}}{2}\right)\right]
$$

\section{VERIFICATION OF THE DEVELOPED EQUATIONS}

Experimental data are used to evaluate the developed equations, (Eqs. 14 and 18). Figures $2 \mathrm{a}$ and $2 \mathrm{~b}$ show the relationship between the theoretical results and the measured experimental data. It can be said that the developed equations prove an acceptable agreement as compared to the observations $\left(\mathrm{R}^{2}=0.91,0.96\right)$ respectively.

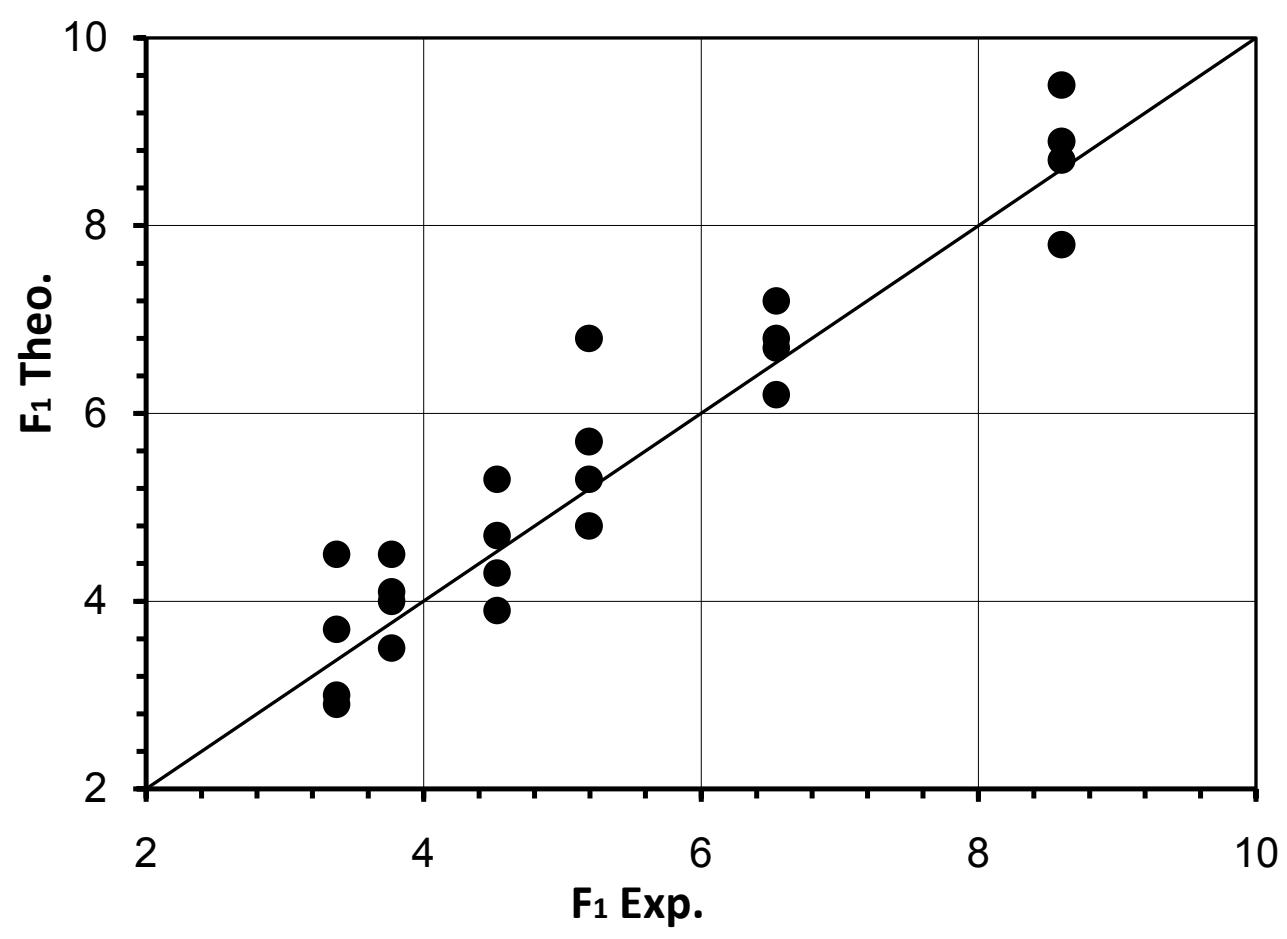

2(a) 


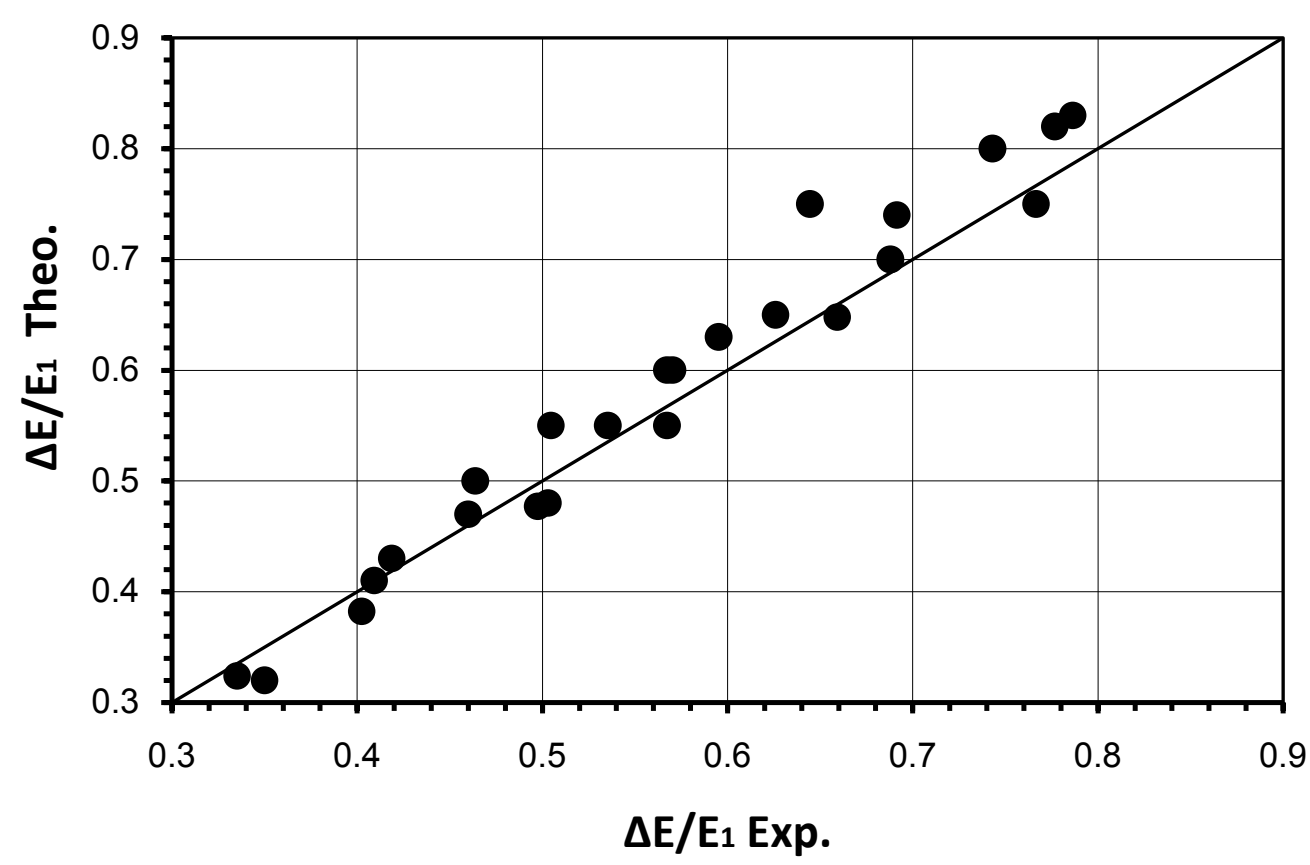

2(b)

Fig 2: Relationship between developed equations and experimental measurements (a) $\mathrm{F}_{1}$ model Eq. (14) (b) $\Delta E / E_{1}$ model Eq.

\section{EXPERIMENTAL RESULTS AND DISCUSSION}

\subsection{Effect of the Relative Depth of the Staggered}

\section{Roughened Elements}

There is an interaction between the flow body and the roughness elements. This interaction depends upon three parameters, which can be listed as follows: 1- the flow velocity, 2- projection area of the roughness elements and 3the percentage of the flow which can be reflected in the adverse direction by the roughness elements. The relations between the initial Froude number; $F_{1}$ and each of the relative jump depth $\mathrm{y}_{2} / \mathrm{y}_{1}$; the relative jump length $\mathrm{L}_{\mathrm{j}} / \mathrm{y}_{1}$ and the relative energy loss $\Delta E / E_{1}$ for different roughened depths $\left(\mathrm{H}_{\mathrm{r}}=0.5,0.75,1.0\right.$, and $\left.1.5 \mathrm{~cm}\right)$ are shown in figures (3a, 3b, and 3c). The figures show also the same relation for the case of smooth bed. It clears from Fig. (3) that the values of the relative jump characteristics including $\mathrm{y}_{2} / \mathrm{y}_{1}, \mathrm{~L}_{\mathrm{j}} / \mathrm{y}_{1}$, $\Delta E / E_{1}$ increase with the increase of the initial $\mathrm{F}_{1}$. The relative roughened depth $\left(\mathrm{H}_{\mathrm{r}}=1.5 \mathrm{~cm}\right)$ gives the minimum values of $\mathrm{y}_{2} / \mathrm{y}_{1}$. It reduces the average values of $\mathrm{y}_{2} / \mathrm{y}_{1}$ by about $22 \%$. the case of $\left(\mathrm{H}_{\mathrm{r}}=1.5 \mathrm{~cm}\right)$ increases the lost energy in comparison with the smooth case by about $14 \%$, morever in comparison with the smooth case, it reduces the values of $\mathrm{L}_{\mathrm{j}} / \mathrm{y}_{1}$ by about $8.1 \%$.

Fig. (4) Shows the relation between $H / G$ and the coefficient of discharge $\mathrm{C}_{\mathrm{d}}$ for the different values of $\mathrm{H}_{\mathrm{r}}$. The case of $\mathrm{H}_{\mathrm{r}}$
$=0.5 \mathrm{~cm}$ gives the maximum values of $\mathrm{C}_{\mathrm{d}}$ in comparison with the smooth case. It increases the average values of $\mathrm{C}_{\mathrm{d}}$ by about $21 \%$.

As seen in the experimental results, the jump characteristics have been improved as the relative depth of the roughness elements, $\mathrm{H}_{\mathrm{r}}$ increased. 


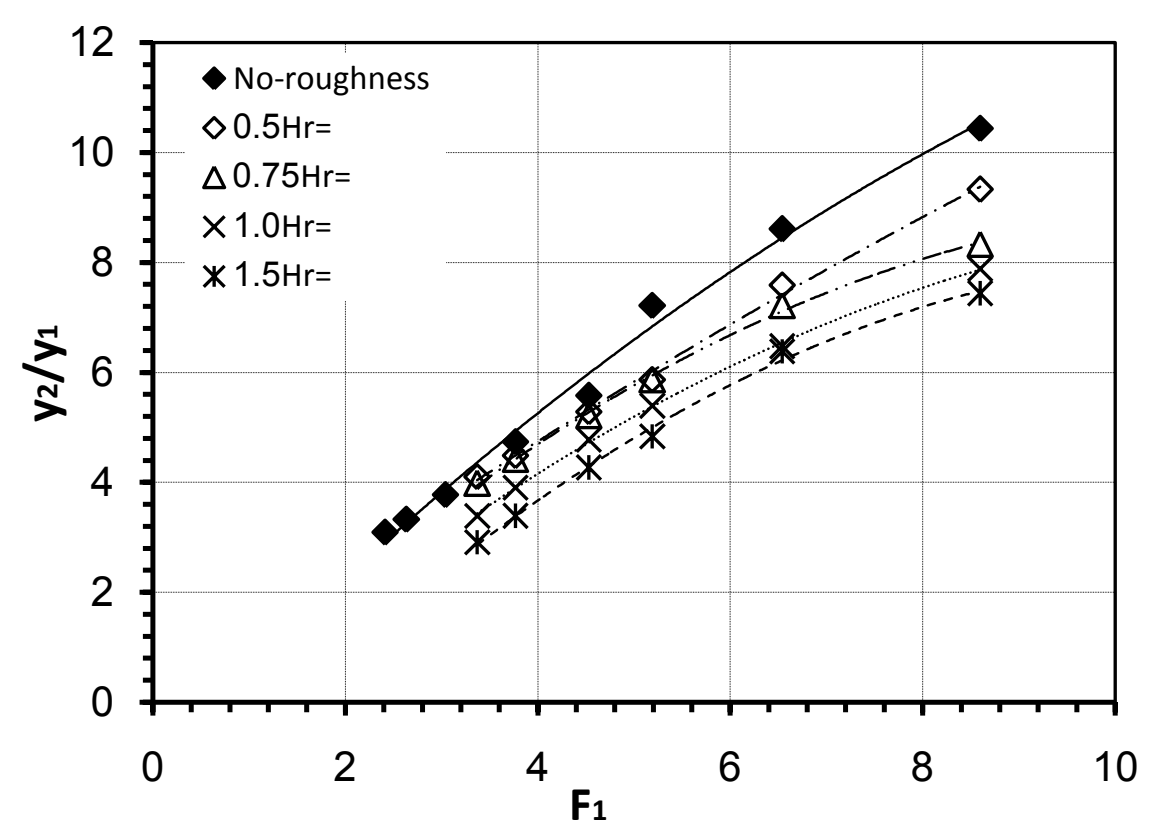

Fig 3a: Relations between $F_{1}$ and $y_{2} / y_{1}$ for different relative staggered roughened depths

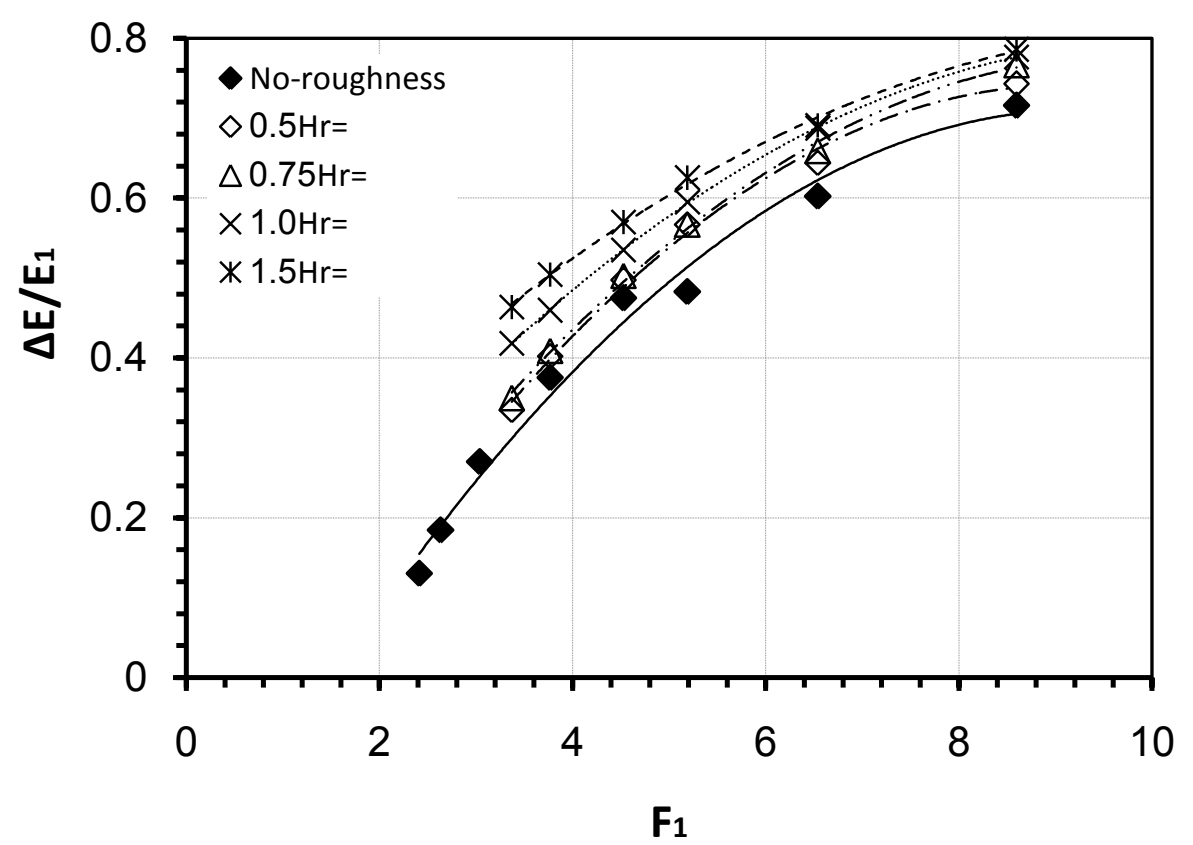

Fig 3b: Relations between $F_{1}$ and $L_{j} / y_{1}$ for different relative staggered roughened depths 


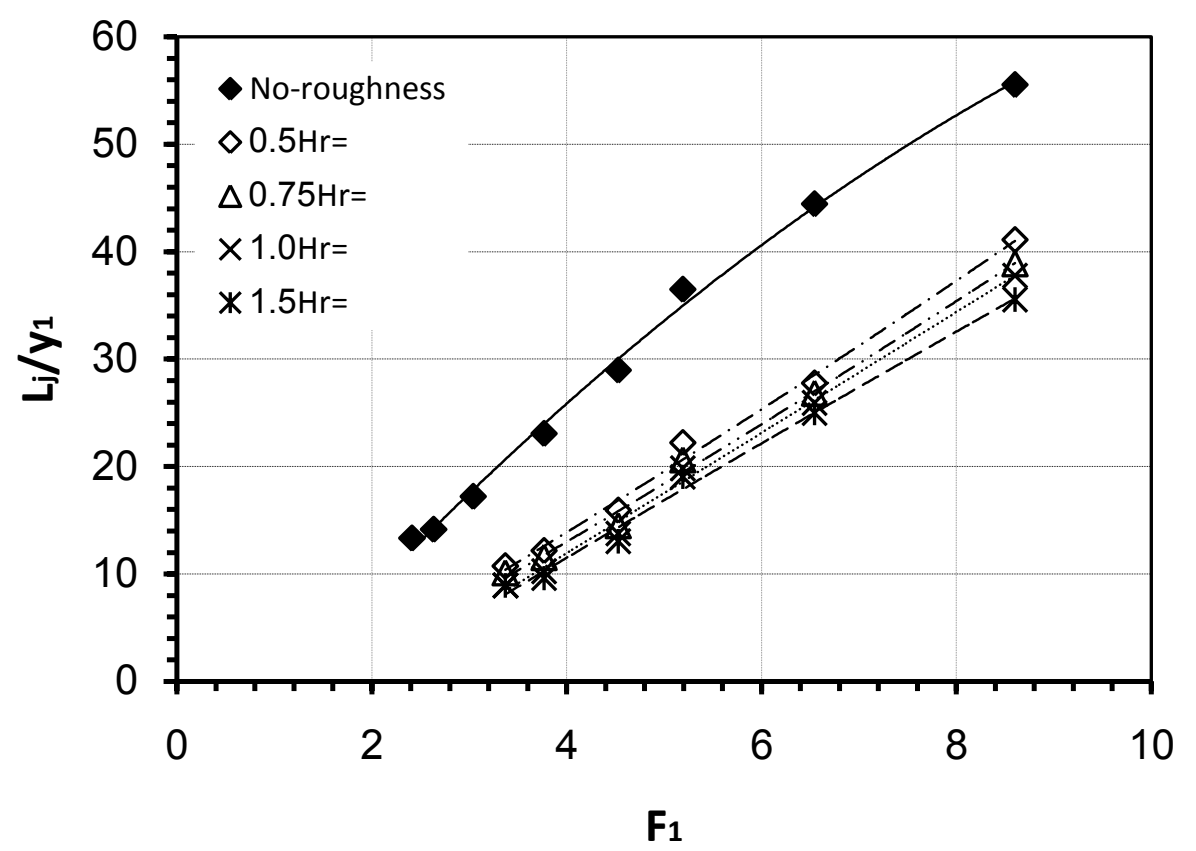

Fig 3c: Relations between $\mathrm{F}_{1}$ and $\Delta E / E_{1}$ for different relative staggered roughened depths

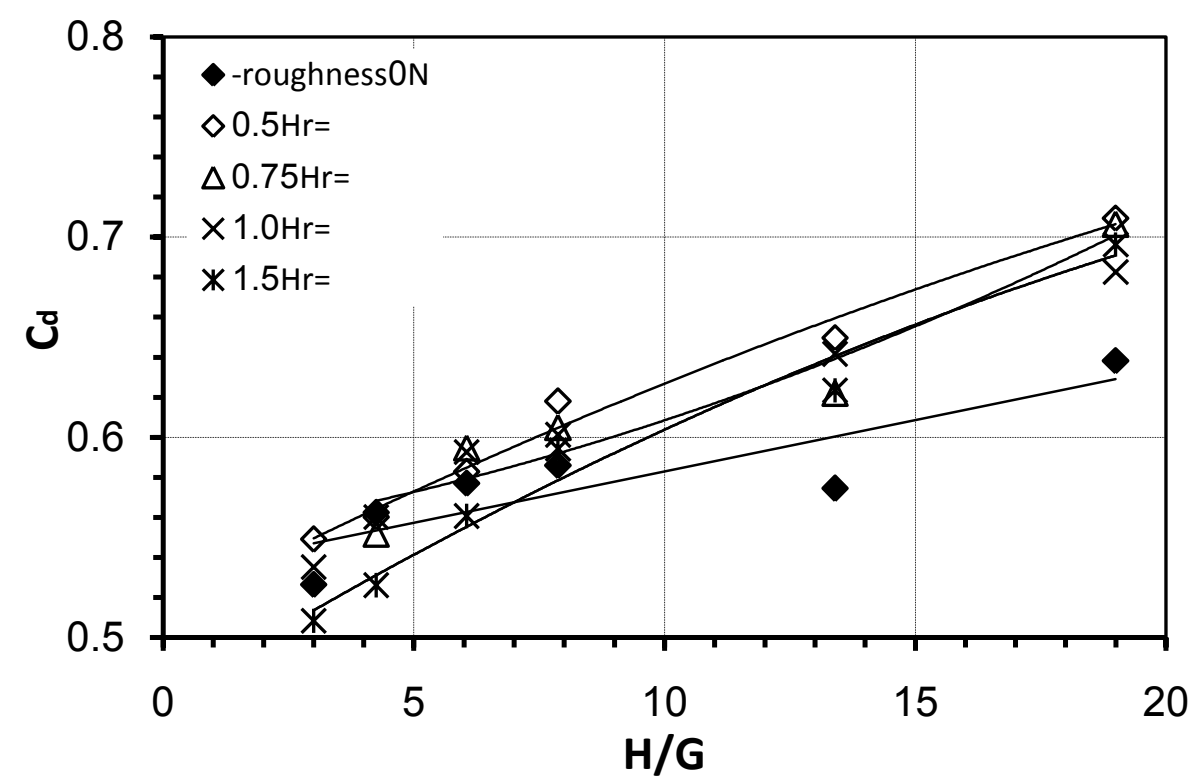

Fig 4: Relations between $H / G$ and $C_{d}$ for different relative staggered roughened depths

\section{STATISTICAL REGRESSION}

Using a regression tool, this simplifies the regression tasks and statistical analysis. The statistical analysis was used to relate the dependent parameters including $\mathrm{y}_{2} / \mathrm{y}_{1}, \mathrm{~L}_{\mathrm{j}} / \mathrm{y}_{1}$; $\Delta E / E_{1}$; and $\mathrm{C}_{\mathrm{d}}$ and other independent ones under the basis of non-liner regression. the statistical equations $(19,20,21$ and 22) were built to predict the different relative jump characteristics including the relative jump depth $\mathrm{y}_{2} / \mathrm{y}_{1}$, the relative jump length $\mathrm{Lj} / \mathrm{y}_{1}$ and the relative energy loss $\Delta E / E_{1}$ for the flow of the studied roughened bed. Figures
$(6,8,10$ and 12) show a comparison between the measured $\mathrm{y}_{2} / \mathrm{y}_{1}, \mathrm{~L}_{\mathrm{j}} / \mathrm{y}_{1} ; \Delta E / E_{1}$; and $\mathrm{C}_{\mathrm{d}}$ and the predicted ones using statistical models Equations (19, 20, 21 and 22), respectively for all experimental measurements. The comparison indicated an acceptable agreement between the model prediction and experimental data. $R^{2}=0.98,0.99,0.94$ and 0.96 , respectively. The residuals of the pervious equations are plotted versus the predicted values as shown in Figs (7, 9,11 , and 13). 


$$
\begin{aligned}
& \frac{y_{2}}{y_{1}}=1.043 F_{1}-1.549 \frac{H_{r}}{y_{1}}-+1.134 \\
& \frac{\Delta E}{E_{1}}=0.062 F_{1}+0.089 \frac{H_{r}}{y_{1}}+0.166 \\
& \frac{L j}{y_{1}}=5.945 F_{1}-3.896 \frac{H_{r}}{y_{1}}-8.780 . \\
& C d=0.014 \frac{H}{G}-0.046 \frac{H_{r}}{y_{1}}+0.404
\end{aligned}
$$

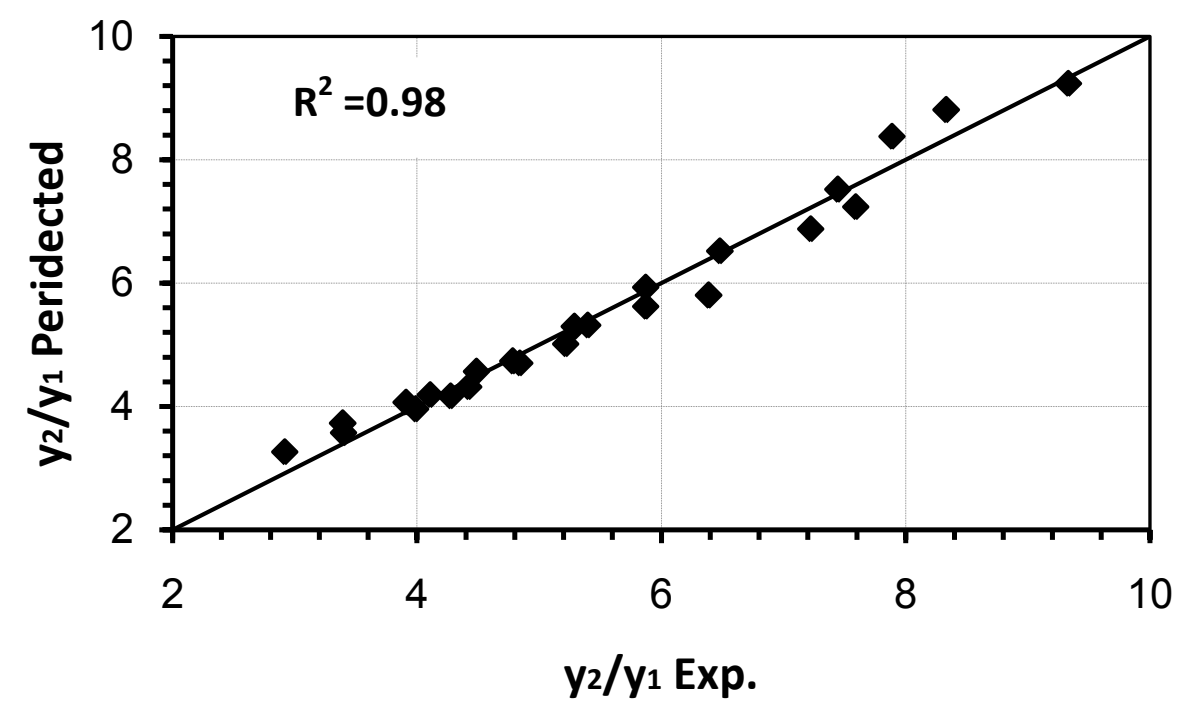

Fig 6 Relation between the measured $y_{2} / y_{1}$ and the predicted ones

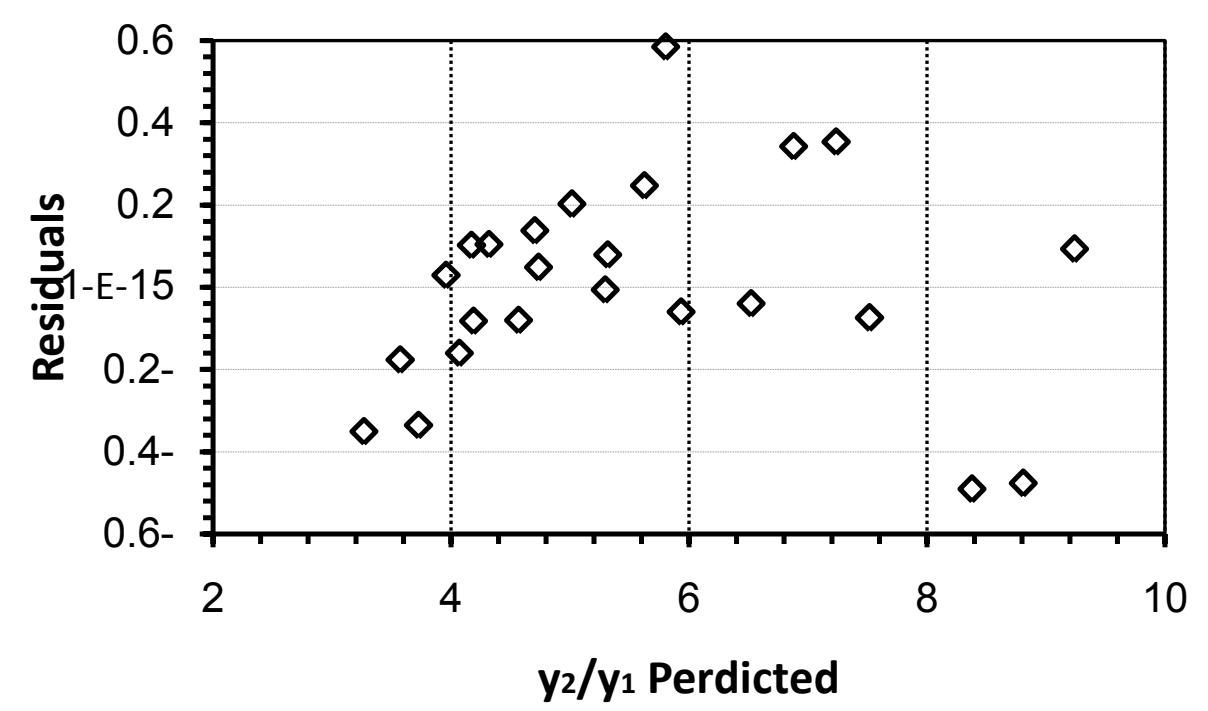

Fig 7 Variations of residuals for different data sets with predicted data Eq. (20) 


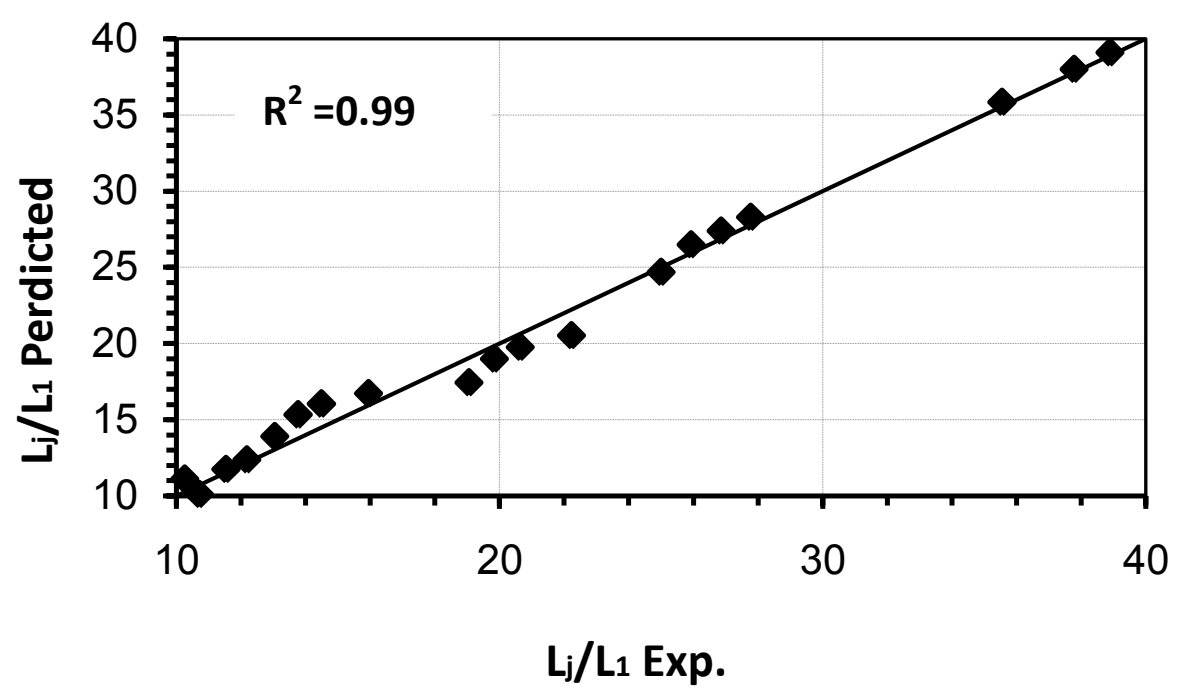

Fig 8 Relation between the measured $\mathrm{L}_{\mathrm{j}} / \mathrm{y}_{1}$ and the predicted ones

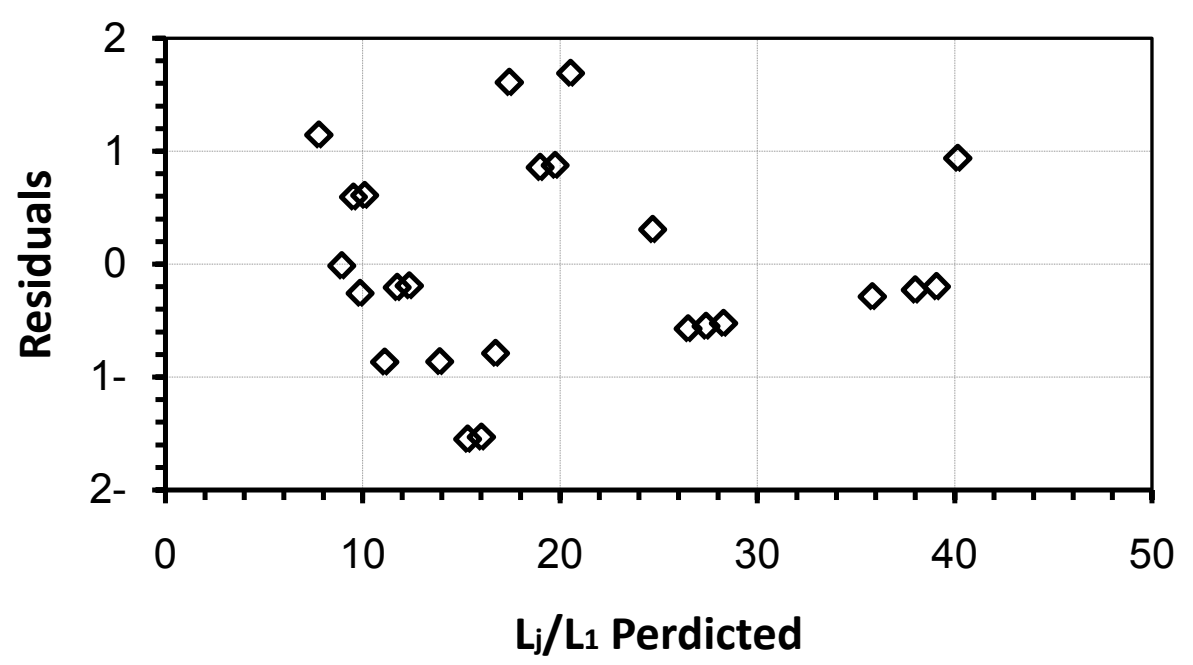

Fig 9 Variations of residuals for different data sets with predicted data Eq. (21)

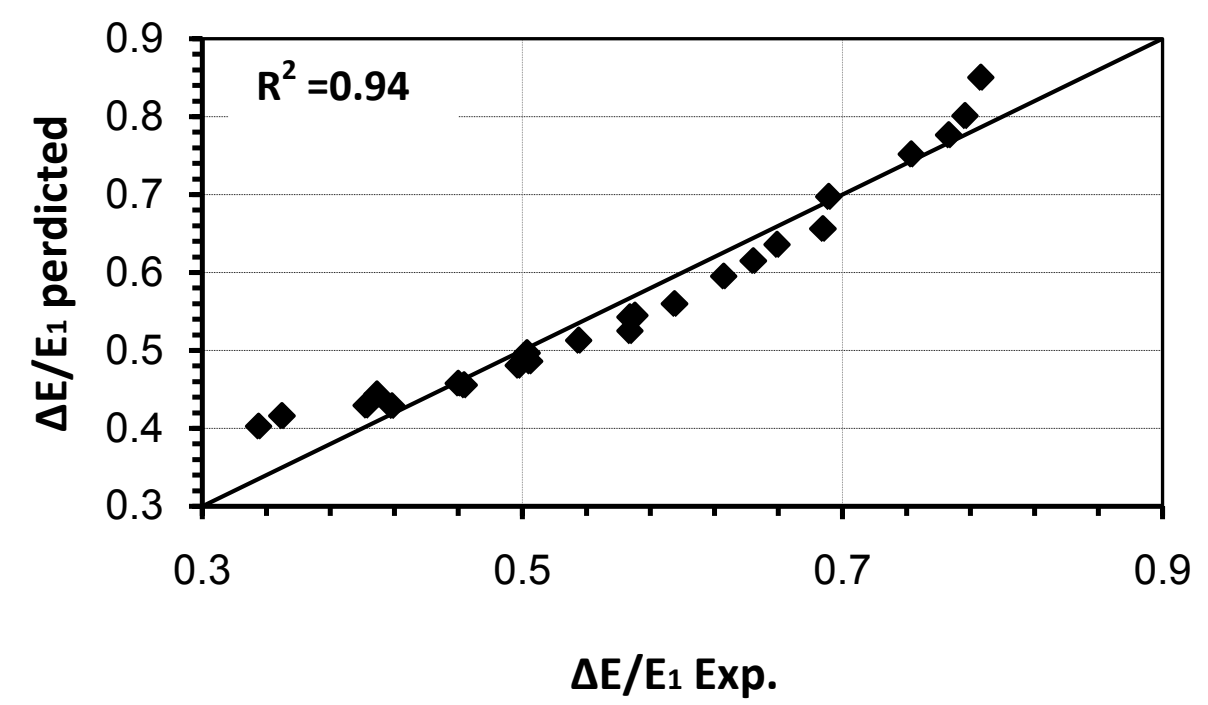

Fig 10 Relation between the measured $\Delta \mathrm{E} / \mathrm{E}_{1}$ and the predicted ones 


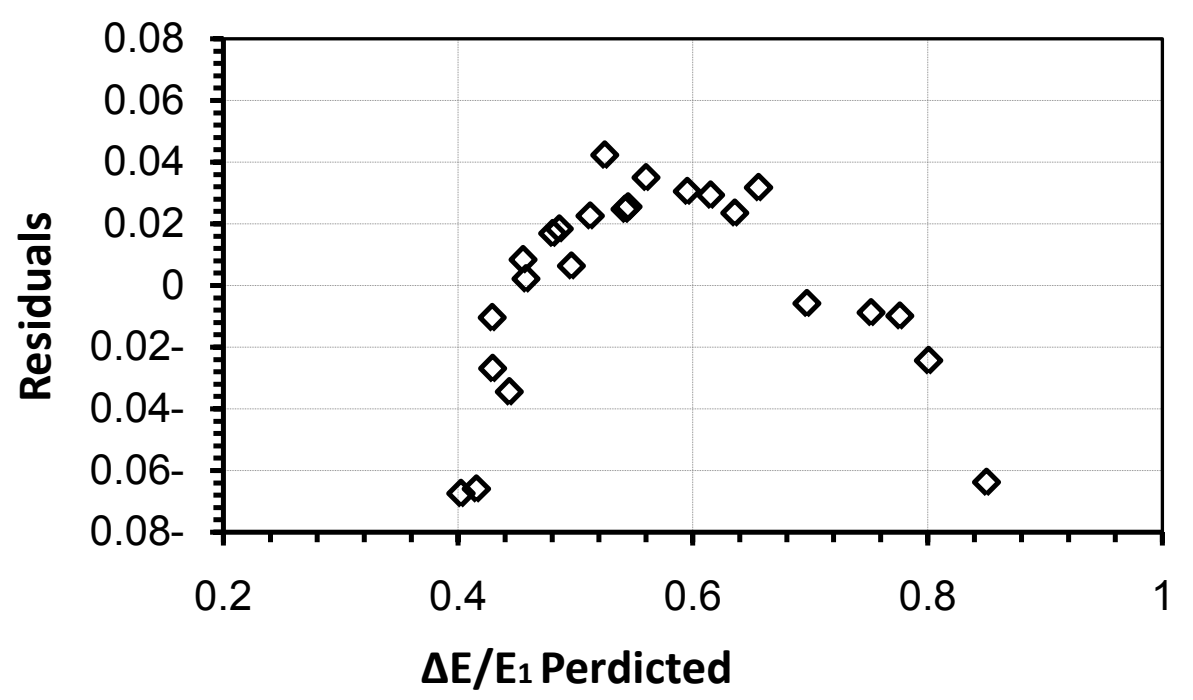

Fig 11 Variations of residuals for different data sets with predicted data Eq. (22)

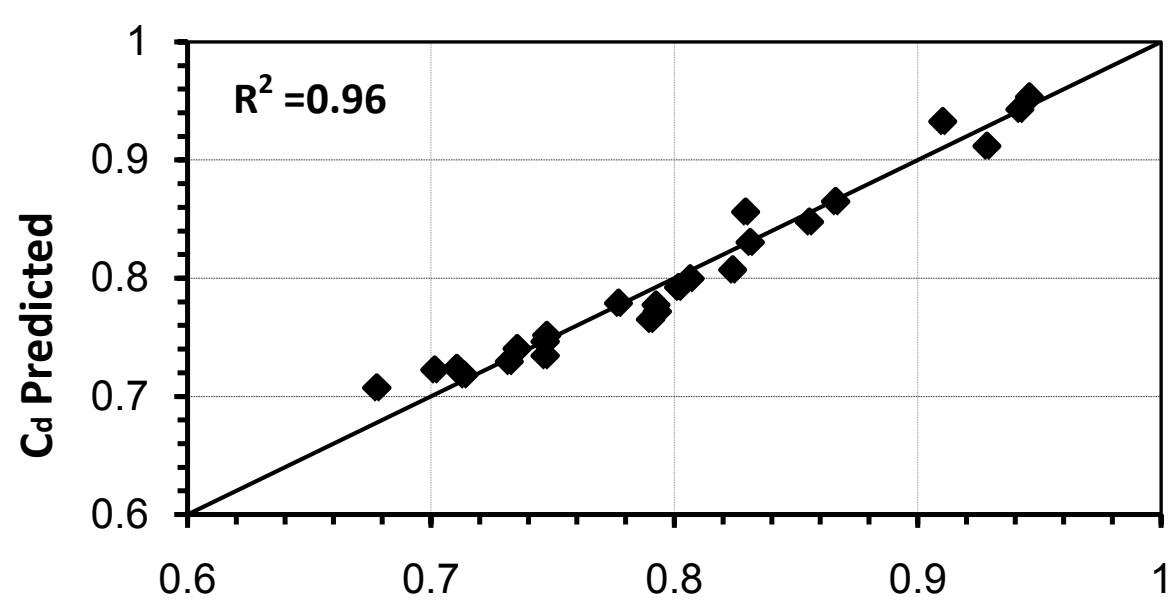

Cd Exp.

Fig 12 Relation between the measured $\mathrm{C}_{\mathrm{d}}$ and the predicted ones

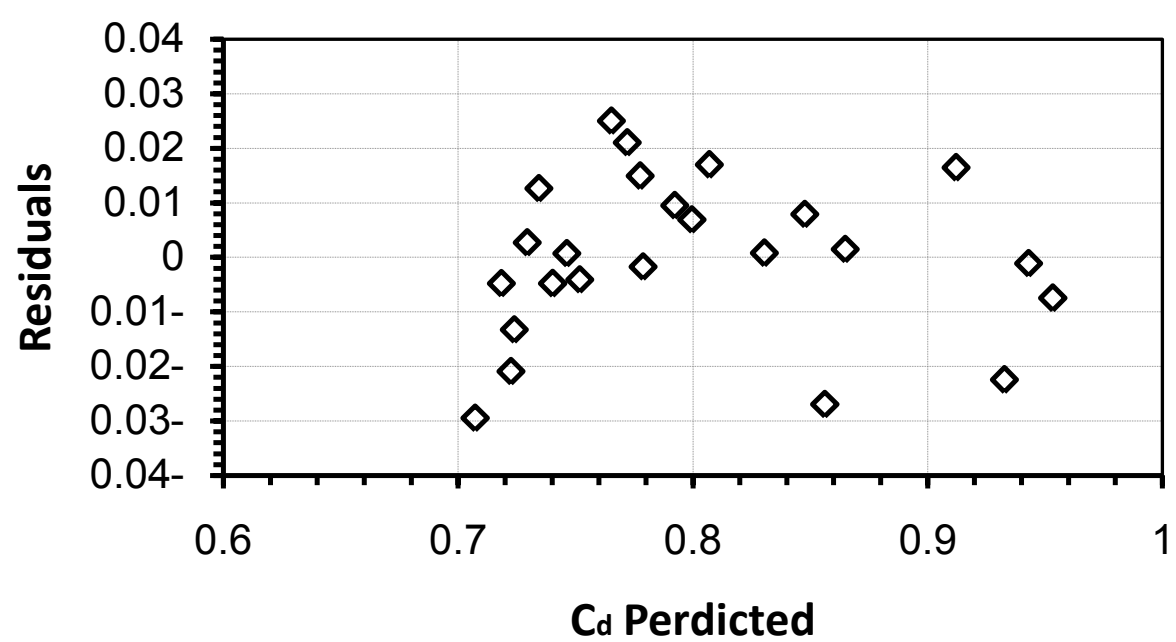

Fig 13 Variations of residuals for different data sets with predicted data Eq. (23) 


\section{CONCLUSIONS}

The experimental work was accompanied to study the characteristics of flow under the effect of staggered roughness elements with different variable depths. To improve the efficiency of the hydraulic jump characteristics, a new roughness shape was tested in the present study. It investigated the effect of the depth of the roughness elements on the Flow characteristics in a rectangular flume. The following conclusions can be listed.

- The case of staggered roughness elements of roughened depth $\left(\mathrm{H}_{\mathrm{r}}=1.5 \mathrm{~cm}\right)$ achieves minimum values of $y_{2} / y_{1}$, reducing the average relative depth of the jump by $22 \%$ in comparison with the case of the smooth bed,

- It gives also the minimum values of the relative jump length $\mathrm{L}_{\mathrm{j}} / \mathrm{y}_{1}$, reducing the average relative length of the jump by $8.1 \%$ in comparison with the smooth bed,

- In addition, it gives the maximum values of the relative energy loss $\Delta \mathrm{E} / \mathrm{E}_{1}$, increasing the average relative energy loss of the jump by $14 \%$.

- The case of staggered roughness elements of roughened depth $\left(\mathrm{H}_{\mathrm{r}}=0.5 \mathrm{~cm}\right)$ increases the coefficient of discharge $\mathrm{C}_{\mathrm{d}}$ by $21 \%$.

- The developed theoretical equations prove an acceptable agreement as compared to the experimental results.

- Prediction equations were developed using the multiple linear regression (MLR) to model the H.J. characteristics and an acceptable agreement was obtained between the predicted and the measured values.

\section{REFERENCES}

[1] Abbaspour, A., Farsadizadeh d., Dalir A.H. and Sadraddini A. A., (2009), "Numerical study of hydraulic jumps on corrugated beds using turbulence models" Turkish J. Eng. Env. Sci. No. 33, pp. 61 72.

[2] Abdelsalam M. W., Hammad, M. E., Khalifa, A. and Abdellateef, M., (1986), "Roughened Bed Stilling Basin", Scientific Bulletin, Faculty of Engineering, Ain Shams University, Cairo, Egypt, No.19, pp. 178-198.

[3] AboulAtta, N., Ezizah, G., Yousif, N. and Fathy S., (2011) "Design of Stilling Basins using Artificial Roughness", J. of Civ. and Env. Eng., vol 3, No. 2, pp. 65-71.

[4] Alhamid, A.A. (1994), "Effective Roughness on Horizontal Rectangular Stilling Basins", Transactions on Ecology and the Environment Vol. 8, WIT Press, ISSN 1743-3541.

[5] Defina, A. and Susin, M., (2008)," Bed friction effects on the stability of a stationary hydraulic jump in a rectangular upward sloping channel", American Institute of Physics, 20.

[6] Ead S.A., Rajaratnam N., (2002), "Hydraulic Jumps on Corrugated Beds", Journal of hydraulic engineering, ASCE., Vol.128, No. (7), pp. 656-663.
[7] Elsebaie, I. H., and Shabayek, S., (2010), "Formation of Hydraulic Jumps on Corrugated Beds" International J. of Civ. \& Env. Eng. Vol.10, No 1, pp. 40-50.

[8] Ezizah, G., Yousif, N. and Mostafa, S., (2012), "Hydraulic Jump on New Roughened Beds", Asian J. of applied Sciences, ISSN 1996-3343 / DOI: 10.3923/ajaps.2012, Malaysia.

[9] Esfahani M.J. and Bejestan M., (2012), "Design of Stilling Basins using Artificial Roughness", J. Civil Eng. Urban. Vol. 2, No. (4), pp. 159-163.

[10] Evicimen, T.U., (2005), " The Effect of Prismatic Roughness Elements on Hydraulic Jump", M.SC. Thesis.

[11] Habib, A.A., and Nassar, M.A., (2013), " Characteristics of Flow and Scour Under The Effect of Curved Steel Roughness Elements", The Egyptian Int. of Eng. Sci. and Technology, Vol. 3 , No. (16).

[12] Hughes, W.C. and Flack, J.E. (1984), "Hydraulic Jump Properties Over a Rough Bed", J. Hydraulic Engineering, ASCE, Vol. 110, No.2, pp.1755-1771.

[13] Leutheusser, H.J. and Schiller, E.J.(1975), "Hydraulic Jump in a Rough Channel", Water Power and Dam Construction, Vol. 27, No. 5, May, pp. 186-191.

[14] Mohamed Ali, H.S., (1991), "Effect of Roughened Bed Stilling Basin on Length of Rectangular Hydraulic Jump", J. Hydraulic Engineering, ASCE, Vol. 117, No. 1, pp. 83-93.

[15] Negm, A.M., El-Tarzy, A.I., Abdellateef, M. and Owais, T.M., (1993), "Optimum Floor Length DS Hydraulic Structures With Staggered Roughness Elements", Eng. Bulletin, Faculty of Eng., Ain Shams University, Cairo, Egypt, Vol. 28, No.1, March, pp. 301-314.

[16] Nikmehr, S. and Tabebordbar, A., (2010), "Hydraulic Jumps on Adverse Slope in Two Cases of Rough and Smooth Bed", Research Journal of Applied Sciences, Engineering and Technology, vol. 2, No. (1), pp. 19-22.

[17] Peterka, A. J., (1978), "Hydraulic Design of Stilling Basin and Energy Dissipators", U.S. Dept. of the Interior, Bureau of Reclamation, Washington, D.C., 25.

[18] Pillai, N.N., Unny, T.E., (1964), "Shapes of Appurtenances in Stilling Basins". Journal of the Hydraulics Division, 90(3):1-12.

[19] Rajaratnam, N., (1964), "The Forced Hydraulic Jump", Water Power and Dam Construction, Vol.16, No, 1.

[20] Rajaratnam, N. (1968), "Hydraulic Jumps on Rough Beds", Trans. Eng. Inst. Canada, Vol 11, No.A-2, May.

[21] Ranga Raju, K.G.; Kitaal, M.K.; Verma, M.S. and Ganeshan, V.R. (1980), "Analysis of Flow Over Baffle Blocks and End Sills", J. Hydraulic Research, Vol. 18, No.3, pp. 227-241.

[22] Sun, Z. and Ellayn, A.F., (2012), "Effect of Prismatic Elements as bed Roughness on Hydraulic Jump 
Characteristics" J. Physical Sciences, Vol. 7(17), pp. $2607-2615$.

[23] Tokyay, N.D., Evcimen, T.U. and Şimşek, C., (2011), "Forced Hydraulic Jump on Non-protruding Rough Beds", Can. J. Civ. Eng., Vol.38, No.(10), pp. 1136-1144. 